\title{
Is pre-fracture functional status better than cognitive level in predicting short-term outcome of elderly hip fracture patients?
}

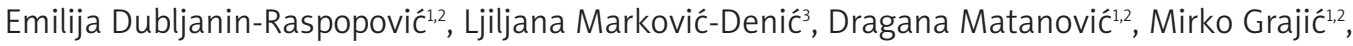 \\ Nevena Krstić ${ }^{1}$, Marko Bumbaširević ${ }^{2,4}$
}

${ }^{1}$ Clinic for Physical Medicine and Rehabilitation, Clinical Centre Serbia, Serbia
2Faculty of Medicine, University of Belgrade, Serbia
${ }^{3}$ Institute of Epidemiology, Faculty of Medicine, University of Belgrade, Serbia
${ }^{4}$ Clinic for Orthopaedic Surgery and Traumatology, Clinical Centre Serbia, Serbia

Submitted: 15 December 2010

Accepted: 20 March 2011

Arch Med Sci 2012; 8, 1: 115-122

DOI: 10.5114 /aoms.2012.27291

Copyright (c) 2012 Termedia \& Banach

\section{Abstract}

Introduction: The aim of the study was to determine to what extent severe cognitive impairment impacts short-term rehabilitation outcomes of elderly patients with proximal hip fracture.

Material and methods: A total of 337 community-dwelling elderly patients with acute hip fracture were observed during a 12-month period at a major teaching hospital in Serbia. Cognitive status was assessed at admission with the Short Portable Mental Status Questionnaire (SPMSQ). Outcome after 4 months was analysed with respect to presence of severe cognitive impairment, defined as an SPMSQ score of < 3. Outcome assessment included presence of postoperative complications, absolute motor Functional Independence Measure (FIM) gain, Activities of Daily Living index (ADL), Instrumental Activities of Daily Living score (IADL), and walking ability.

Results: An SPMSQ score of < 3 was observed in 36 patients (10.7\%) with acute hip fracture. Patients with an SPMSQ score of $<3$ achieved worse short-term outcomes regarding all observed variables. However, cognitive status was found to be an independent predictor only with respect to mortality at 4 months (odds ratio $(\mathrm{OR})=0.969,95 \%$ confidence interval $(\mathrm{Cl})=0.947-0.992, p=0.009)$. In contrast, pre-fracture motor FIM independently predicted mortality $(\mathrm{OR}=2.982$, $95 \% \mathrm{Cl}=1.271-7.000, p=0.012)$, and preserved walking ability at 4 months follow-up ( $\mathrm{OR}=0.945,95 \% \mathrm{Cl}=0.912-0.980, p=0.002)$. Correspondingly, pre-fracture ADL was an independent predictor of absolute motor FIM gain at 4 months follow-up (OR $=0.175,95 \% \mathrm{Cl}=0.405-11.426, p=0.035)$.

Conclusions: Failure to consider functional status prior to fracture might overestimate the impact of cognitive status on functional outcome of hip fracture patients.

Key words: hip fractures, cognitive disorders, rehabilitation, treatment outcome.

\section{Introduction}

Hip fractures represent one of the most common and potentially devastating injuries among the elderly. As the population is ageing, the incidence of hip fractures will continue to rise, as will the proportion of patients with cognitive impairment [1]. Cognitive impairment is recognized in 35\%

\author{
Corresponding author: \\ Emilija Dubljanin Raspopovic \\ MD, MSC \\ Clinic for Physical Medicine \\ and Rehabilitation \\ Clinical Centre Serbia \\ Pasterova 2 \\ 11000 Belgrade, Serbia \\ Phone: +381637767368 \\ Fax: +381(11)3610090 \\ E-mail: edubljaninraspopovic@ \\ gmail.com
}


to $61 \%$ of hip fracture patients during hospitalization [2]. Physiological changes due to stress of the injury, hospitalization, and side effects of analgesics and anaesthesia are possibly responsible for the new onset of cognitive impairment [3], which might explain the three to six times higher prevalence of cognitive impairment in hip fracture patients compared to other hospitalized older patients [2]. It is well recognized that successful inpatient rehabilitation accounts for most functional recovery in improving patients' mobility and activities of daily living $[4,5]$. Despite this, an unsubstantiated perception among many health care professionals that cognitively impaired patients cannot benefit from rehabilitation still exists. A number of studies have found that cognitive impairment is a negative predictor of rehabilitation outcome in hip fracture patients [4, 6, 7]. Other studies have suggested that cognitively impaired patients benefit from rehabilitation after a hip fracture [8-10]. However, these studies address outcome only with respect to presence of cognitive impairment, but not to its severity. Prospective studies specifically assessing the influence of severe cognitive impairment on outcome after hip fracture are lacking, and their results are conflicting [11-13]. While two studies report that cognitive status per se does not play a major role with respect to outcome, but rather discharge to a rehabilitation unit [11], or pre-fracture motor capacity [12], Soderqvist et al. [13] state that severe cognitive impairment is related to poor outcome with regard to walking ability, ability to perform activities of daily living, and mortality. Acknowledging the impact of severe cognitive impairment on post-acute rehabilitation outcomes of elderly patients with hip fracture is the first step in providing optimal treatment for this vulnerable group of patients. Our objective was to determine to what extent severe cognitive impairment affects shortterm rehabilitation outcomes of elderly patients with proximal hip fracture.

\section{Material and methods}

All patients who consecutively presented with hip fracture at the Clinics for Orthopedic Surgery and Traumatology (COST), Clinical Center of Serbia, from March 2009 to March 2010 were prospectively enrolled in an open cohort study. Exclusion criteria were as follows: age $<65$ years, pathological fracture, major concomitant injuries, multiple trauma such as a vehicle accident, imminent death due to an end-stage disease, and inability to walk prior to fracture. Patients who were treated nonoperatively due to high surgical risk were also excluded from the study. After discharge from COST patients were transferred to a rehabilitation hospital. The study was conducted according to the Helsinki Declaration [14], and approved by the Ethics
Committee of the Medical Faculty at Belgrade University in Serbia.

Subjects were assessed via patient/proxy interview within $48 \mathrm{~h}$ of admission regarding pre-fracture living conditions, cognitive status, pre-fracture walking ability, and pre-fracture functional status. In all patients, depending on overall postoperative health status, early mobilization was encouraged on the first postoperative day with weight-bearing as tolerated.

Cognitive status at admission was assessed with the Short Portable Mental Status Questionnaire (SPMSQ). The 10-item questionnaire has good validity and reliability, and is easy and quick to administer $[11,13,15]$. According to SPMSQ cognitive level is categorized as intact for 8 to 10 correct answers, mildly impaired for 6 to 7 correct answers, moderately impaired for 3 to 5 correct answers, and severely impaired for less than 3 correct answers. Choosing the cut-off limit of fewer than 3 correct answers has already been used in previous studies conducted on hip fracture patients [11, 13, 16, 17]. We used these criteria to compare the outcomes for patients with severe cognitive impairment (SPMSQ <3) with the outcomes of patients who were cognitively intact, or had only mild or moderate cognitive impairment (SPMSQ $\geq 3$ ). In patients with an SPMSQ score < 3, all observed variables, except for the cognitive status, were collected from a proxy.

Pre-fracture living conditions were recorded as either independent, or as institutionalized. Preinjury walking ability was classified as able to walk outdoors, only indoors, or unable to walk. Use of walking aids was also assessed. We compared two groups of patients: those who were walking without a walking aid, or with just a cane, and those who needed two canes, or a walker. Pre-fracture functional level was assessed by the motor subscale of the Functional Independence Measure (FIM - FIM is a trademark and UDSMR is a service mark of the Uniform Data System for Medical Rehabilitation, a division of UB Foundation Activities Inc). The 13-item motor FIM rates the patient's independence in self-care (feeding, grooming, bathing, dressing upper and lower body, toileting), sphincter control (bladder management and bowel management), transfer (bed, chair, wheelchair transfer, toilet, and tub or shower transfer), and locomotion (walking, climbing stairs) [18]. Ratings for each item ranged from one (total assistance) to seven (complete independence). Independence in activities of daily living (bathing, dressing, toilet use, transferring, urine and bowel continence, eating) was assessed with the Katz Activities of Daily Living index [19]. An ADL index of A indicates independence in all six functions, while index $B$ indicates independence in all but one of the six functions. Indices $C$ to $G$ indicate dependence in bathing, and 
at least one other function [20]. The Lawton Instrumental Activities of Daily Living (IADL) Scale was used to assess independent living skills [21]. The IADL scale score ranges from 0 to 8 , with 8 representing complete independence in IADL. These skills are considered more complex than the basic activities of daily living as measured by the Katz Index of ADL. The American Society of Anesthesia's (ASA) rating of operative risk was used to group patients' physical status into one of 5 categories, ranging from 1 (healthy) to 5 (moribund) [22]. No patient in our study was graded moribund. For the purpose of this study, two rating categories were used: grade 1 or 2 , and grade 3 or 4 . This approach has been previously used in hip fracture patients [23].

During the primary hospital stay, surgical method, presence of postoperative complications, number of deaths prior to discharge, and length of hospital stay were recorded.

Patient and/or proxies were followed up at 4 months via telephone interview. Smith et al. [24] found that telephone interviews using FIM are a reliable method to assess follow-up function. Our main outcome measure was the absolute motor FIM gain, which is the difference between 4-month follow-up motor FIM and discharge motor FIM. Walking ability, dependence on walking aids, ADL index, IADL score, general medical complications, and mortality were also assessed. Observed postoperative medical complications were new-onset delirium, pneumonia, cerebrovascular event, myocardial infarction, pulmonary embolism, urinary tract infection, deep wound infection, pressure sores, and prosthetic dislocation. Regarding the number of complications we compared two groups of patients ( 0 complications versus $\geq 1$ complications). All assessments were carried out by the coordinator of the study (EDR), except for the American Society of Anesthesia's (ASA) classification, and the type of fracture, which were categorized by the attending anaesthesiologist, and responsible surgeon, respectively. The tester had no influence on any part of the treatment of the patient.

\section{Statistical analysis}

All analyses used a two-tailed significance level of $p<0.05$. For the analysis of continuous variables (conveyed as mean \pm standard deviation) in independent groups Student's $t$ test and Mann-Whitney test were used. Chi-square test and Fisher's exact test were used to test categorical variables (expressed as numbers and percentages of patients). Multiple regression analyses were performed to further assess factors predicting mortality, preserved ambulatory status and functional gain at 4-month follow-up. Only those univariate predictors with significance level $p<0.1$ were subsequently tested in multivariate models.
Multivariate logistic regression analysis (backward conditional procedure) was performed to reveal factors independently related to mortality, and ambulatory status. The relative importance of various predictors of outcome is presented as the odds ration (OR) with $95 \%$ confidence interval. All multivariate regression models were tested with the Hosmer-Lemeshow goodness-of-fit test, and showed good, non-significant values. Multivariate linear regression (backward procedure) was used to identify factors predicting absolute motor FIM gain. Assumptions of linearity, normally distributed errors, and uncorrelated errors were checked and met. Analyses were performed using the Statistical Package for Social Sciences, version 8.0 (SPSS Inc, Chicago, IL, USA).

\section{Results}

\section{Study population and baseline data}

Table I shows baseline characteristics of hip fracture patients followed in this study with respect to cognitive status. During the study period a total of 337 patients met eligibility criteria, and agreed to participate in the study. The age range of patients was $65-96$ years, mean age $79.0 \pm 7.4$ years. Three treatment modalities were used: 199 patients (59.1\%) underwent hemiarthroplasty (bipolar prosthesis), 125 (37.1\%) underwent closed reduction internal fixation (dynamic hip screw), and 13 patients (3.9\%) had a total hip replacement (THR). Bone cement was used in all patients with arthroplasty. The criteria for receiving THR, besides preexisting joint disease, medium/high activity levels, and reasonable life expectancy, was also preserved cognitive function.

At admission severe cognitive impairment was identified in $36(10.7 \%)$ of 337 patients with acute hip fracture. Patients in the group with an SPMSQ score $<3$ were older, were more often admitted from an institution, and were more often household ambulators. They also had lower scores for pre-fracture motor FIM, IADL, and a lower ADL index. No other significant differences were noted between the two cognitive groups of patients.

A total of 31 patients (9.2\%) died before hospital discharge. The total number of patients who died prior to 4-month follow-up was 70 (20.8\%), while 35 patients (13.1\%) were lost before 4 months, leaving 232 patients in the study group (68.8\%).

\section{Postoperative outcomes}

\section{Complications}

Out of 337 observed patients, $46.9 \%$ developed a complication. Postoperative complications were encountered in more patients with an SPMSQ score of $<3(88.9 \%)$ than in patients with an SPMSQ 
score of $\geq 3(41.9 \%, p=0.000)$. Type of complications varied between the groups concerning incidence of in-hospital mortality, 4-month mortality, delirium, and pressure ulcers (Table II). Of all tested independent variables, age was the most influential predictor of 4-month mortality, followed by cognitive status, and pre-fracture motor FIM score (Table III). The model correctly predicted outcome

Table I. Baseline data in relation to cognitive function at admission assessed with the Short Portable Mental Status Questionnaire

\begin{tabular}{|c|c|c|c|}
\hline Parameter & $\begin{array}{c}\text { SPMSQ }<3 \\
(n=36)\end{array}$ & $\begin{array}{c}\text { SPMSQ } \geq 3 \\
(n=301)\end{array}$ & Value of $p$ \\
\hline $\begin{array}{l}\text { Number of patients } \\
(N=337)\end{array}$ & s 36 (10.7\%) & 301 (89.3\%) & \\
\hline Age [year]* & $77.95 \pm 7.50$ & $80.83 \pm 6.39$ & 0.027 \\
\hline \multicolumn{4}{|l|}{ Gender $^{\dagger}$} \\
\hline Male & 7 (19.4\%) & $60(20.0 \%)$ & \multirow[t]{2}{*}{0.937} \\
\hline Female & $29(80.6 \%)$ & $239(80.0 \%)$ & \\
\hline \multicolumn{4}{|l|}{ Pre-injury residence $^{\dagger}$} \\
\hline Home & $30(88.2 \%)$ & $298(99 \%)$ & \multirow[t]{2}{*}{0.003} \\
\hline Institution & $4(11.8 \%)$ & $3(1 \%)$ & \\
\hline \multicolumn{4}{|l|}{$\mathrm{ASA}^{\dagger}$} \\
\hline 1,2 & $15(42.9 \%)$ & $178(59.5 \%)$ & \multirow[t]{2}{*}{0.059} \\
\hline 3,4 & $20(57.1 \%)$ & $121(40.5 \%)$ & \\
\hline Motor FIM* & $72.09 \pm 17.10$ & $86.05 \pm 9.59$ & 0.000 \\
\hline \multicolumn{4}{|l|}{ Walking ability ${ }^{\dagger}$} \\
\hline $\begin{array}{l}\text { Community } \\
\text { ambulators }\end{array}$ & $24(72.7 \%)$ & $270(89.67 \%)$ & \multirow[t]{2}{*}{0.009} \\
\hline $\begin{array}{l}\text { Household } \\
\text { ambulators }\end{array}$ & $9(27.3 \%)$ & $31(10.3 \%)$ & \\
\hline \multicolumn{4}{|l|}{ Walking aids ${ }^{\dagger}$} \\
\hline None/1 cane & $30(90.9 \%)$ & $286(95 \%)$ & \multirow[t]{2}{*}{0.404} \\
\hline $\begin{array}{l}\text { Two canes/ } \\
\text { walkers }\end{array}$ & $3(9.1 \%)$ & $15(5 \%)$ & \\
\hline \multicolumn{4}{|l|}{$\mathrm{ADL}^{\dagger}$} \\
\hline$A-B$ & $11(34.4 \%)$ & $249(82.7 \%)$ & \multirow[t]{2}{*}{0.000} \\
\hline$C-G$ & $21(65.6 \%)$ & $52(17.3 \%)$ & \\
\hline $\mathrm{IADL}^{*}$ & $1.50 \pm 1.63$ & $5.49 \pm 2.45$ & 0.000 \\
\hline \multicolumn{4}{|l|}{ Type of fracture ${ }^{\dagger}$} \\
\hline Femoral neck & $24(66.7 \%)$ & $186(62.5 \%)$ & \multirow[t]{2}{*}{0.569} \\
\hline Intertrochanteric & $12(33.3 \%)$ & $115(37.5 \%)$ & \\
\hline \multicolumn{4}{|c|}{ Type of surgical procedure ${ }^{\dagger}$} \\
\hline Hemiarthroplasty & y $23(63.9 \%)$ & $176(58.5 \%)$ & \multirow[t]{3}{*}{0.776} \\
\hline Internal fixation & $12(33.3 \%)$ & $113(37.5 \%)$ & \\
\hline $\begin{array}{l}\text { Total hip } \\
\text { replacement }\end{array}$ & $1(2.8 \%)$ & $12(4.0 \%)$ & \\
\hline
\end{tabular}

for $80.1 \%$ of patients. The overall significance of the model was $p=0.000\left(\chi^{2}=52.607, \mathrm{df}=3\right)$.

\section{Walking ability}

Before fracture, all patients were able to walk. Among survivors at the 4-month follow-up, information on walking ability was available for 224 patients (83.9\%). Preserved walking ability was noted in 9 patients (64.5\%) with an SPMSQ score of $<3$, while this was the case in 193 patients (91.9\%) with an SPMSQ score of $\geq 3$ ( $p=0.000)$. Multivariate logistic regression analysis revealed that only pre-fracture motor FIM score was an independent predictor of preserved walking ability at 4-month follow-up (OR $=0.945 ; 95 \% \mathrm{Cl}=$ $0.912-0.980 ; p=0.002$ ). The model correctly predicted outcome for $90.2 \%$ of patients. The significance of the model was $p=0.000\left(\chi^{2}=20.046\right.$, $d f=3)$.

Table II. Complications in relation to cognitive function

\begin{tabular}{|c|c|c|c|}
\hline Parameter & $\begin{array}{c}\text { SPMSQ }<3 \\
(n=36)\end{array}$ & $\begin{array}{c}\text { SPMSQ } \geq 3 \\
(n=301)\end{array}$ & Value of $p$ \\
\hline \multicolumn{4}{|c|}{ Complications $^{\dagger}$} \\
\hline Yes & $126(41.9 \%)$ & $32(88.9 \%)$ & \multirow[t]{2}{*}{0.000} \\
\hline No & $175(58.1 \%)$ & $4(11.1 \%)$ & \\
\hline \multicolumn{4}{|c|}{ In-hospital mortality ${ }^{\dagger}$} \\
\hline Yes & $23(7.6 \%)$ & $8(22.2 \%)$ & \multirow[t]{2}{*}{0.010} \\
\hline No & $278(92.4 \%)$ & $28(77.8 \%)$ & \\
\hline \multicolumn{4}{|c|}{ Four-month mortality ${ }^{\dagger}$} \\
\hline Yes & $19(52.8 \%)$ & $57(16.9 \%)$ & \multirow[t]{2}{*}{0.000} \\
\hline No & $17(47.2 \%)$ & $250(83.1 \%)$ & \\
\hline \multicolumn{4}{|l|}{ Delirium $^{\dagger}$} \\
\hline Yes & $15(41.7 \%)$ & $20(6.6 \%)$ & \multirow[t]{2}{*}{0.000} \\
\hline No & $21(58.3 \%)$ & $281(93.4 \%)$ & \\
\hline \multicolumn{4}{|c|}{ Pressure ulcers ${ }^{\dagger}$} \\
\hline Yes & $13(36.1 \%)$ & $40(13.3 \%)$ & \multirow[t]{2}{*}{0.001} \\
\hline No & 23 (63.9\%) & $261(86.7 \%)$ & \\
\hline
\end{tabular}

${ }^{\dagger}$ Values are given as the number of patients with the percentage in parentheses

Table III. Variables independently associated with mortality within 4 months after hip fracture according to multivariate logistic regression

\begin{tabular}{|lcc|}
\hline Predictors & $\begin{array}{c}\text { Odds ratio } \\
(95 \% \text { confidence interval) }\end{array}$ & Value of $p$ \\
\hline $\begin{array}{l}\text { Motor FIM before } \\
\text { fracture }\end{array}$ & $2.982(1.271-7.000)$ & 0.012 \\
\hline Age & $1.118(1.068-1.171)$ & 0.000 \\
\hline SPMSQ & $0.969(0.947-0.992)$ & 0.009 \\
\hline
\end{tabular}


Prior to fracture, 24 patients (72.7\%) with an SPMSQ score of $<3$ were community walkers, while this was the case in 270 patients $(89.67 \%)$ with an SPMSQ score of $\geq 3$. Of the survivors at the 4-month follow-up, only 1 patient (7.1\%) was able to walk outdoors, while this was the case in 109 patients (52.4\%) with better cognitive status ( $p=0.000)$. Information was available for 222 patients (83.2\%).

Before fracture, 30 patients $(90.9 \%)$ in the group with an SPMSQ score < 3, and 286 patients (95\%) with an SPMSQ $\geq 3$ were walking with a walking aid, or just a stick.

At 4-month follow-up, the corresponding numbers were 2 (22.2\%) and 108 (56.0\%), respectively $(p=0.047)$. Analysis on use of walking aids was available for $202(75.7 \%)$ of the survivors at 4-month follow-up.

\section{Functional outcome}

Among survivors at the 4-month follow-up, information on functional gain was available for 222 patients (83.2\%). As expected, patients with an SPMSQ score of $\geq 3$ achieved a larger absolute motor FIM gain at 4-month follow-up compared to patients with an SPMSQ score $<3(21.7 \pm 12.3$ vs. $13.36 \pm 15.2, p=0.016)$. Among all variables, only pre-fracture ADL index was identified by multiple linear regression as an independent predictor of absolute motor FIM gain at 4 months follow-up $(\mathrm{OR}=0.175,95 \% \mathrm{Cl}=0.405-11.426, p=0.035$, $R^{2}=0.035, p=0.035$ ).

Of the survivors, information on ADL index and IADL score at 4-month follow-up was available for 224 patients (83.9\%). The ADL index and IADL score among patients with an SPMSQ score of $\geq 3$ were significantly higher than those among patients with an SPMSQ score of $\geq 3(p=0.000)$.

\section{Discussion}

Comparison of our results with outcomes across other studies was difficult due to the different scales and thresholds used to define cognitive impairment, different outcome measures used to assess functional outcomes, and different followup periods.

It seems undeniable that elderly hip fracture patients with higher cognitive level achieve better short-term rehabilitation outcomes. Our study revealed higher absolute motor FIM gains in the group of patients with an SPMSQ of $\geq 3$. However, even patients with severe cognitive impairment improved their functional abilities as suggested by the positive motor FIM gain during the observed period. Moreover, pre-fracture ability to perform $A D L$, and not cognitive status at admission, was an independent predictor of motor FIM gain.
The association between cognitive level and functional gain has been recognized in several studies. Similarly to our results, other authors have also reported favourable functional outcome results in hip fracture patients with cognitive impairment [12, $25,26]$. Beloosesky et al. [12] found that pre-fracture motor and not cognitive level was the most important predictive factor for motor gain after hip fracture. Goldstein et al. [25] found similar motor FIM gain in both cognitively intact and impaired patients with hip fracture. Likewise, Diamond et al. [26] found that cognitive impairment in orthopaedic and neurological patients was not significantly related to the change in FIM score.

In contrast to the previously mentioned studies, Hershkovitz et al. [4] reported that cognitively intact patients achieved a significantly better functional recovery, and that cognitive function, nutritional status, and the pre-injury functional level were independent predictors of discharge FIM. Lenze et al. [5] also found that lower cognitive scores were significantly correlated with lower improvement in motor FIM, and outcome. Heruti et al. [6] confirmed that impaired cognitive status at admission lowered the rehabilitation outcome of elderly hip fracture patients, and that cognitive impairment was strongly and directly associated with functional gain in these patients.

Our research revealed that the ability to perform basic and instrumental activities of daily living was significantly better in patients with an SPMSQ score of $\geq 3$. Also, walking ability was significantly better in patients with a higher cognitive level at the time of 4-month follow-up. Several other authors have substantiated that the cut-off level of less than three correct answers in the SPMSQ is a strong predictor of poor outcome with regard to performance of activities of daily living, walking ability, and mortality in patients with hip fracture $[13,16,17]$. In particular, we found that $35.7 \%$ of the patients with an SPMSQ score of $<3$ were non-ambulatory at 4-month follow-up. Furthermore, the average ADL score in this group of patients was $1.57 \pm 1.34$, which indicated almost full dependence. Our results are consistent with those of other investigators [11, 17, 27]. Söderqvist et al. [13] found that $36 \%$ of patients with an SPMSQ score of $<3$ were confined to a wheelchair, while almost $39 \%$ were totally dependent in ADL 1 year following hip fracture. Blomfeldt et al. [16], and Al-Ani et al. [11] reported similar findings among patients with an SPMSQ score of $<3$.

Despite the fact that a score of SPMSQ $<3$ was a predictor of poor outcome in regard to walking ability in our study, motor FIM before fracture and not cognitive status has been identified as the only variable independently related to preserved walking ability at 4-month follow-up. Correspondingly, 
Al-Ani et al. [11] did not find cognitive impairment to be a predictor of preserved walking ability at 4 months postoperatively, but rather walking ability before fracture and discharge to rehabilitation units. In contrast, other authors reported that dementia can predict ambulatory status [28, 29]. Different cognitive assessment instruments and cut-off levels might explain the disagreement in results concerning the ability of cognitive status to predict walking ability in the above-mentioned studies. We believe that the fact that all of our patients were ambulatory prior to fracture, which confirms their preserved motor function, also explains their capacity recovery of walking ability after hip fracture. However, as revealed in our study, pre-fracture higher motor function, as expressed by higher pre-fracture functional scores, allows for higher functional gain, and better walking ability recovery during the post-acute rehabilitation period.

The mortality rate within 4 months of hip fracture in this study was $20.8 \%$. Reported mortality rates after hip fracture vary between 9\% and 30\% [30-34]. In our study, patients with an SPMSQ score of $<3$ had a significantly higher mortality rate compared to patients with an SPMSQ score of $\geq 3$. This is in conformity with findings of previously published studies of patients with hip fracture using SPMSQ for cognitive assessment [11, 13, 17]. In line with earlier reports $[13,35]$, cognitive impairment was found to be a good predictor of mortality.

The postoperative complication rate was higher in the group of patients with an SPMSQ score of $<3$. This finding is in accordance with the results of Beloosesky et al. [12]. A higher incidence of pressure ulcers in hip fracture patients with severe cognitive impairment was confirmed by Söderqvist et al. [27].

The Mini-Mental State Examination (MMSE) is the most widely used screening test in dementia [36]. It consists of 13 items, and includes manual handling and drawing. It is preferable for the patient to be in a sitting position when the test is conducted, which is a major weakness when assessing bed-bound patients. The SPMSQ is a validated instrument for assessing cognitive function, with a similar sensitivity and specificity to that of the MMSE [15, 37]. In a review article, Smith et al. [38] concluded that the SPMSQ test is easy to administer with good inter-rater reliability and test-retest reliability. Strömberg et al. [39] reported fluctuation in cognitive function during hospitalization of patients with hip fracture. However, this fluctuation was more pronounced in patients with mild and moderate cognitive impairment than in patients with severe or intact cognitive function at admission. They showed that only $2-3 \%$ of patients with severe cognitive impairment at admission were lucid at the time of discharge. Consequently, choos- ing the cut-off limit of fewer than 3 correct answers makes inclusion of patients with temporary impairment less probable.

Not recognizing severe cognitive impairment in routine health care might have several implications. The association between cognitive impairment and delirium is well recognized [40]. Furthermore, authors such as Gustafson et al. [41] have suggested that delirium can be prevented and treated. Cognitive status should also be taken into account when selecting the surgical method [42]. Finally, there is evidence in the literature that older people with a hip fracture and impaired cognitive ability receive insufficient nursing care, and consequently suffer from a higher incidence of complications $[27,43]$. Therefore, routine assessment of cognitive status in the acute setting can help in defining optimal treatment strategies, and improve patients' care.

Certain limitations and strengths of the study should be addressed. To the best of our knowledge, no previous study has compared functional gain in respect to cognitive status assessed with SPMSQ, and there are only two studies that used SPMSQ to assess rehabilitation outcome in hip fracture patients [11, 13].

The limitations of the study are as follows. Only short-term rehabilitation outcomes were observed. An explanation for the short-term methodological method is that the acute rehabilitation period is the most decisive part of rehabilitation predicting longterm outcome, which indicates the necessity of short-term follow-up introduction in the evaluation of hip fracture patients $[44,45]$. We did not compare the place of residence upon discharge between the two cognitive groups, which is a recognized outcome measure [3]. The reason is that the decision for institutionalization after hip fracture in Serbia is more often dependant on non-medical factors, such as cultural perception, and available financial support. We believe that the fact that $90.9 \%$ of our patients with severe cognitive impairment walked without a walking aid, or only with a stick prior to fracture, is not completely a reflection of their superb walking ability, but partly a consequence of rather inadequate accessibility to, and low awareness of the benefit of, different walking aids. Nevertheless, our results speak in favour of an explicit decline of walking ability in this group of patients after surgery. Also, data from patients with severe cognitive impairment were collected only from proxies, with no reliability testing of the proxy given information performed.

In conclusion, our study revealed that severe cognitive impairment, defined as an SPMSQ score of $<3$, is an unquestionable obstacle in geriatric rehabilitation. However, despite the fact that hip fracture patients with severe cognitive impairment can- 
not achieve the same level of recovery as patients with higher cognitive levels, they do benefit from rehabilitation, and exhibit functional gains. Pre-fracture functional status rather than cognitive level at admission has a more important role in predicting short-term functional outcome. Failure to consider functional status prior to fracture might overestimate the impact of cognitive status of hip fracture patients on functional outcome.

Identifying hip fracture patients with severe cognitive impairment using a reliable, valid, and brief cognitive screening instrument may assist in efficiently allocating rehabilitation resources. Future research is needed to define specific rehabilitation needs and create treatment interventions for patients with severe cognitive impairment in order to maximize the rehabilitation potential of this vulnerable group of patients.

\section{Acknowledgments}

This work was supported by the Ministry of Education and Science, contract No. 175046, 2011-2014.

\section{References}

1. Tinetti ME. Factors associated with serious injury during falls by ambulatory nursing home residents. J Am Geriatr Soc 1987; 35: 644-8.

2. Gruber-Baldini AL, Zimmerman S, Morrison RS, et al. Cognitive impairment in hip fracture patients: timing of detection and longitudinal follow-up. J Am Geriatr Soc 2003; 51: 1227-36.

3. Muir SW, Yohannes AM. The impact of cognitive impairment on rehabilitation outcomes in elderly patients admitted with a femoral neck fracture: a systematic review. J Geriatr Phys Ther 2009; 32: 24-32.

4. Hershkovitz A, Kalandariov Z, Hermush V, Weiss R, Brill S. Factors affecting short-term rehabilitation outcomes of disabled elderly patients with proximal hip fracture. Arch Phys Med Rehabil 2007; 88: 916-21.

5. Lenze EJ, Munin MC, Dew MA, et al. Adverse effects of depression and cognitive impairment on rehabilitation participation and recovery from hip fracture. Int J Geriatr Psychiatry 2004; 19: 472-8.

6. Heruti RJ, Lusky A, Barell V, Ohry A, Adunsky A. Cognitive status at admission: does it affect the rehabilitation outcome of elderly patients with hip fracture? Arch Phys Med Rehabil 1999; 80: 432-6.

7. Givens JL, Sanft TB, Marcantonio ER. Functional recovery after hip fracture: the combined effects of depressive symptoms, cognitive impairment, and delirium. J Am Geriatr Soc 2008; 56: 1075-9.

8. Lenze EJ, Skidmore ER, Dew MA, et al. Does depression, apathy or cognitive impairment reduce the benefit of inpatient rehabilitation facilities for elderly hip fracture patients? Gen Hosp Psychiatry 2007; 29: 141-6.

9. Huusko TM, Karppi P, Avikainen V, Kautiainen H, Sulkava R. Randomised, clinically controlled trial of intensive geriatric rehabilitation in patients with hip fracture: subgroup analysis of patients with dementia. BMJ 2000; 321: 1107-11.
10. Rolland $Y$, Pillard $F$, Lauwers-Cances $V$, Busquère $F$, Vellas B, Lafont C. Rehabilitation outcome of elderly patients with hip fracture and cognitive impairment. Disabil Rehabil 2004; 26: 425-31.

11. Al-Ani AN, Flodin L, Söderqvist A, et al. Does rehabilitation matter in patients with femoral neck fracture and cognitive impairment? A prospective study of 246 patients. Arch Phys Med Rehabilitation 2010; 91: 51-7.

12. Beloosesky Y, Grinblat J, Epelboym B, Weiss A, Grosman B, Hendel D. Functional gain of hip fracture patients in different cognitive and functional groups. Clin Rehabil 2002; 16: 321-8.

13. Söderqvist A, Miedel R, Ponzer S, Tidermark J. The influence of cognitive function on outcome after a hip fracture. J Bone Joint Surg Am 2006; 88: 2115-23.

14. Declaration. WMADH, [http://www.wma.net/en/30publications/10policies/b3/index.html].

15. Pfeiffer E. A short portable mental status questionnaire for the assessment of organic brain deficit in elderly patients. J Am Geriatr Soc 1975; 23: 433-41.

16. Blomfeldt R, Törnkvist H, Ponzer S, Söderqvist A, Tidermark J. Internal fixation versus hemiarthroplasty for displaced fractures of the femoral neck in elderly patients with severe cognitive impairment. J Bone Joint Surg Br 2005; 87: 523-9.

17. Tidermark J, Ponzer S, Svensson O, Söderqvist A, Törnkvist $\mathrm{H}$. Internal fixation compared with total hip replacement for displaced femoral neck fractures in the elderly. A randomised, controlled trial. J Bone Joint Surg Br 2003; 85: 380-8.

18. Granger CV HB, Keith RA, Zielezny M, Sherwin F. Advances in functional assessment for medical rehabilitation. In: Topics in geriatric rehabilitation. Lewis CB (ed.). Baltimore, Aspen Publishing 1986; 59-74.

19. Katz S, Ford AB, Moskowitz RW, Jackson BA, Jaffe MW. Studies of illness in the aged. The Index of Adl: a standardized measure of biological and psychosocial function. JAMA 1963; 185: 914-9.

20. Katz S, Akpom CA. 12. Index of ADL. Med Care 1976; 14 (5 Suppl): 116-8.

21. Lawton MP, Brody EM. Assessment of older people: selfmaintaining and instrumental activities of daily living. Gerontologist 1969; 9: 179-86.

22. Owens WD, Felts JA, Spitznagel EL Jr. ASA physical status classifications: a study of consistency of ratings. Anesthesiology 1978; 49: 239-43.

23. Paksima N, Koval KJ, Aharanoff G, et al. Predictors of mortality after hip fracture: a 10-year prospective study. Bull NYU Hosp Jt Dis 2008; 66: 111-7.

24. Smith PM, Illig SB, Fiedler RC, Hamilton BB, Ottenbacher KJ. Intermodal agreement of follow-up telephone functional assessment using the functional independence measure in patients with stroke. Arch Phys Med Rehabil 1996; 77: 431-5.

25. Goldstein FC, Strasser DC, Woodard JL, Roberts VJ. Functional outcome of cognitively impaired hip fracture patients on a geriatric rehabilitation unit. J Am Geriatr Soc 1997; 45: 35-42.

26. Diamond PT, Felsenthal G, Macciocchi SN, Butler DH, LallyCassady D. Effect of cognitive impairment on rehabilitation outcome. Am J Phys Med Rehabil 1996; 75: 40-3.

27. Söderqvist A, Ponzer S, Tidermark J. Cognitive function and pressure ulcers in hip fracture patients. Scand I Caring Sci 2007; 21: 79-83.

28. Hagino T, Sato E, Tonotsuka H, Ochiai S, Tokai M, Hamada Y. Prediction of ambulation prognosis in the elderly after hip fracture. Int Orthop 2006; 30: 315-9. 
29. Hirose J, Ide J, Yakushiji T, et al. Prediction of postoperative ambulatory status 1 year after hip fracture surgery. Arch Phys Med Rehabil 2010; 91: 67-72.

30. Goldacre MJ, Roberts SE, Yeates D. Mortality after admission to hospital with fractured neck of femur: database study. BMJ 2002; 325: 868-9.

31. Formiga F, Lopez-Soto A, Sacanella E, Coscojuela A Suso S, Pujol R. Mortality and morbidity in nonagenarian patients following hip fracture surgery. Gerontology 2003; 49: 41-5.

32. Hasegawa Y, Suzuki S, Wingstrand H. Risk of mortality following hip fracture in Japan. J Orthop Sci 2007; 12: 113-7.

33. Melton LJ 3rd, Therneau TM, Larson DR. Long-term trends in hip fracture prevalence: the influence of hip fracture incidence and survival. Osteoporos Int 1998; 8: 68-74.

34. Todd CJ, Palmer C, Camilleri-Ferrante C, et al. Differences in mortality after fracture of hip. BMJ 1995; 311: 1025.

35. Marottoli RA, Berkman LF, Leo-Summers L, Cooney LM Jr. Predictors of mortality and institutionalization after hip fracture: the New Haven EPESE cohort. Established Populations for Epidemiologic Studies of the Elderly. Am J Public Health 1994; 84: 1807-12.

36. Folstein MF, Folstein SE, McHugh PR. "Mini-mental state". A practical method for grading the cognitive state of patients for the clinician. J Psychiatr Res 1975; 12: 189-98.

37. Fitten LJ, Lusky R, Hamann C. Assessing treatment decision-making capacity in elderly nursing home residents. J Am Geriatr Soc 1990; 38: 1097-104.

38. Smith MJ, Breitbart WS, Platt MM. A critique of instruments and methods to detect, diagnose, and rate delirium. J Pain Symptom Manage 1995; 10: 35-77.

39. Strömberg L, Lindgren U, Nordin C, Ohlén G, Svensson O. The appearance and disappearance of cognitive impairment in elderly patients during treatment for hip fracture. Scand J Caring Sci 1997; 11: 167-75.

40. Furlaneto ME, Garcez-Leme LE. Delirium in elderly individuals with hip fracture: causes, incidence, prevalence, and risk factors. Clinics (Sao Paulo) 2006; 61: 35-40.

41. Gustafson Y, Lundström M, Bucht G, Edlund A. Delirium in old age can be prevented and treated [Swedish]. Tidsskr Nor Laegeforen 2002; 122: 810-4.

42. van Dortmont LM, Douw CM, van Breukelen AM, et al. Outcome after hemi-arthroplasty for displaced intracapsular femoral neck fracture related to mental state. Injury 2000; 31: 327-31.

43. Söderqvist A, Strömberg L, Ponzer S, Tidermark J. Documenting the cognitive status of hip fracture patients using the Short Portable Mental Status Questionnaire. I Clin Nurs 2006; 15: 308-14

44. Duke RG, Keating JL. An investigation of factors predictive of independence in transfers and ambulation after hip fracture. Arch Phys Med Rehabil 2002; 83: 158-64.

45. Fiedler RC, Granger CV, Russell CF. UDS(MR)SM: followup data on patients discharged in 1994-1996. Uniform Data System for Medical Rehabilitation. Am J Phys Med Rehabil 2000; 79: 184-92. 